\title{
Upregulation of miR-195 increases the sensitivity of breast cancer cells to Adriamycin treatment through inhibition of Raf-1
}

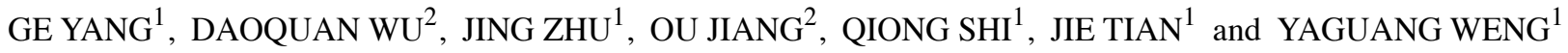 \\ ${ }^{1}$ Key Laboratory of Diagnostic Medicine Designated by the Chinese Ministry of Education and \\ School of Diagnostic Medicine, Chongqing Medical University, Chongqing; ${ }^{2}$ Department of \\ Nephrology, The Second People's Hospital, Neijiang, Sichuan, P.R. China
}

Received March 4, 2013; Accepted May 8, 2013

DOI: $10.3892 /$ or.2013.2532

\begin{abstract}
Chemotherapy is an important option for the treatment of advanced breast cancer, but multidrug resistance is one of the major obstacles in the clinical control of breast cancer. The present study investigated the effects of the miR-195-led gene pathway in the sensitization of breast cancer cells to treatment with the chemotherapeutic drug Adriamycin. Breast cancer cell lines and tissue specimens (obtained from chemotherapy-sensitive or resistant patients) as well as a normal breast cell line were used to assess expression of miR-195, Raf-1, Bcl-2 and P-glycoprotein mRNA and/or mRNA. miR-195 mimics, inhibitor and Raf-1 siRNA were used to transfect breast cancer MCF-7 and MCF-7/ADR cells (an Adriamycinresistant MCF-7 subline) for cell viability, apoptosis and gene expression analysis. The data showed that miR-195 expression was low in breast cancer cells and multidrug-resistant breast cancer tissues, which was associated with reduced Raf-1 expression in vitro and ex vivo. Induction of miR-195 expression promoted tumor cell apoptosis and inhibited breast cancer cell viability, but induced the sensitivity of breast cancer cells to Adriamycin treatment and was associated with inhibition of Raf-1 expression in breast cancer cells. Moreover, knockdown of Raf-1 expression had similar effects of miR-195 mimics on breast cancer cells, both of which were able to suppress Bcl-2 and P-glycoprotein expression in breast cancer cells. The data from the current study demonstrated that expression of miR-195 was inversely associated with Raf-1 expression in breast cancer cell lines and tissue specimens, and that Raf-1 is the target gene of miR-195. Thus, expression of miR-195 or knockdown of Raf-1 can similarly reduce tumor cell survival but increase apoptosis through downregulation of Raf-1 and Bcl-2 and P-glycoprotein expression. In conclusion, this gene
\end{abstract}

Correspondence to: Professor Yaguang Weng, Key Laboratory of Diagnostic Medicine Designated by the Chinese Ministry of Education and School of Diagnostic Medicine, Chongqing Medical University, Medical School Road, Yuzhong, Chongqing 400014, P.R. China

E-mail: yaguangweng@hotmail.com

Key words: breast carcinoma, Adriamycin resistance, microRNA, Raf-1, tissues samples pathway mediated the sensitivity of breast cancer cells to Adriamycin treatment.

\section{Introduction}

Breast cancer is the most common malignancy in women and is a significant worldwide health problem, accounting for approximately 1.3 million new cases and more than 450,000 cancer-related deaths annually in the world (1). Although recent advancements in early detection, prevention and treatments have effectively reduced breast cancer incidence and improved patient survival, a number of patients are still diagnosed at advanced stages of the disease and chemotherapy is the mainstream method of treatment against these advanced diseases. However, nearly $50 \%$ of such patients develop multidrug resistance (MDR) to chemotherapeutic agents during the course of treatment (2). Previous studies have demonstrated different mechanisms responsible for drug resistance, such as drug inactivation, extrusion of the drug by enhanced drug efflux pumps, or changes in drug target during the course of treatment (3-5). Thus, novel approaches to discover molecular targeting therapeutic agents and to re-sensitize the existing drugs to therapy may aid in effectively controlling advanced breast cancer and may improve the prognosis of these patients.

Therefore, our research focused on microRNAs (miRNAs), which are a novel class of endogenous non-coding small RNAs, and function in post-transcriptional regulation of the target gene expressions by binding to the target mRNA to inhibit its translation and/or to degrade the target mRNA molecules (6). Altered expression of different miRNAs has been demonstrated to play an important role in cancer development and progression, as well as in drug resistance. Thus, detection of miRNA was used as a biomarker for early detection of tumorigenesis, drug treatment outcome, prediction of prognosis and disease progression (7). Nevertheless, our research focused mainly on aberrant expression and functions of miRNAs in drug responses. Indeed, previous studies have shown that dysregulation of miRNA expression and function affected the sensitivity of various types of cancer to chemotherapies $(8,9)$. For example, miR-34a expression was able to modulate expression of Bcl-2 and cyclin D1 proteins, and responded to the chemosensitivity of breast cancer MCF-7 cells to docetaxel treatment (10). miR-451 and miR-27 were 
shown to be involved in the resistance of MCF-7 cells to the chemotherapeutic drug doxorubicin by mediated MDR-1 expression $(11,12)$. Thus, targeting of miRNA expression could be used as a novel therapeutic approach for the treatment of breast cancer $(13,14)$.

In the present study, we investigated a particular miRNA, miR-195, which is localized at chromosome 17p13.1 and clustered with other miRNAs, such as miR-497, to form the miR-15 family (15). Previous studies suggested that miR-195 plays a tumor-suppressor role in various types of cancer. Following overexpression in different cancer cells, miR-195 was able to suppress cell cycle progression and tumor cell invasion, but sensitized the tumor cells to treatment with a different anticancer drug $(16,17)$. Thus, we first determined the role of miR-195 in the development of anticancer drug resistance in breast cancer cells and then the underlying molecular mechanism. Subsequently, we searched the GenBank database for identification of the target gene of miR-195 and found that Raf-1 could be a potential target of miR-195.

Proto-oncogene serine/threonine-protein kinase (Raf-1) functions as a part of the MAPK/ERK signal transduction pathway. Once activated, Raf-1 phosphorylates and activates MEK1 and MEK2 protein kinases and then, in turn, phosphorylates and activates the serine/threonine-specific protein kinases ERK1 and ERK2 to control expression of various genes (such as Bcl-2 and P-glycoprotein) in the regulation of cell cycle, cell migration, apoptosis and differentiation (18-21). To date, there has been no report showing Raf-1 mutations in the clinic, but Raf-1 overexpression has frequently been reported in different human tumors (22). Several studies have shown that inhibition of key kinases of the Ras/Raf/MEK/Erk signaling pathway were able to regulate tumor cell proliferation and apoptosis $(18,23)$. Thus, in this study, we investigated whether and how miR-195 targets Raf-1 expression to sensitize breast cancer cells to Adriamycin treatment.

\section{Materials and methods}

Breast cancer tissue samples. We obtained tissue specimens from 17 breast cancer patients at the Second People's Hospital in Neijiang, Sichuan, China. The tissue specimens were available from previously untreated patients who received an Adriamycin-containing regimen for at least six months as adjuvant therapy. The chemotherapy regimen consisted of four 21-day cycles of AC (doxorubicin, $60 \mathrm{mg} / \mathrm{m}^{2}$ on day 1; cyclophosphamide, $600 \mathrm{mg} / \mathrm{m}^{2}$ on day 1) followed by four 21-day cycles of docetaxel $\left(100 \mathrm{mg} / \mathrm{m}^{2}\right.$ on day 1$)$ or six 21 -day cycles of FAC (5 fluorouracil, $500 \mathrm{mg} / \mathrm{m}^{2}$ on day 1 ; doxorubicin, $50 \mathrm{mg} / \mathrm{m}^{2}$ on day 1 ; cyclophosphamide, $500 \mathrm{mg} / \mathrm{m}^{2}$ on day 1 ), under the treatment of which 10 patients had a recurrence at least 6 months after their primary occurrence and were classed as multidrug-resistant, while the other seven patients did not. The drug-resistant or -sensitive tumor tissues were resected and used for this study. In addition, the 17 noncancerous breast tissues were also collected from the Second People's Hospital. The tissues were surgically resected and snap-frozen and stored in liquid nitrogen until use. All cases of breast cancer were pathologically confirmed. All patients provided written informed consent for the use of their tissues and this study was approved by the Hospital's Committee of Human Subject
Protection. Clinicopathological characteristics of these patients are presented in Table I.

Cell lines and culture. A human breast cancer cell line MCF-7 and a human mammary gland epithelial cell line HBL-100 were obtained from KeyGEN Biotech Co. (Nanjing, China). To generate the multidrug-resistant subline MCF-7/ADR, MCF-7 cells were established by serial passages and incubations with increasing Adriamycin concentrations and were maintained in the presence of $500 \mathrm{ng} / \mathrm{ml}$ Adriamycin, as previously described (24), and reached a multidrug-resistant phenotype. These cell lines were maintained in Dulbecco's modified Eagle's medium (DMEM; Invitrogen) with $10 \%$ fetal bovine serum (FBS) (both from Invitrogen, Carlsbad, CA, USA) and penicillin/streptomycin at $37^{\circ} \mathrm{C}$ in a humidified atmosphere with $5 \% \mathrm{CO}_{2}$.

RNA isolation and quantitative reverse transcriptase-polymerase chain reaction ( $q R T-P C R)$. Total cellular RNA from tissues and cultured cells were isolated using a TRIzol Reagent (Invitrogen) according to the manufacturer's instructions. Prior to RNA isolation, freezing tissues were cut into $5 \mathrm{~mm}^{3}$ pieces of each sample and then grinded into finely ground particles. The concentration of these RNA samples was quantitated by measuring the absorbance at 260 vs. $280 \mathrm{~nm}$. Next, the RNA samples were further isolated with a mirPremier miRNA isolation kit (mirVana miRNA isolation kit from Ambion, Austin, TX, USA). The stem-loop reverse transcription was performed to amplify the mature miR-195 using the RT primer, 5'-TGTCAGGCAACCGTATTCACCGGAGTGGT GGGAAG-3' and U6 small RNA with a U6 RT primer, 5'-CGCTTCACGAATTTGCGTGTCAT-3'. Subsequently, reverse transcription was carried out at $25^{\circ} \mathrm{C}$ for $10 \mathrm{~min}, 42^{\circ} \mathrm{C}$ for $1 \mathrm{~h}$, and $85^{\circ} \mathrm{C}$ for $5 \mathrm{~min}$ using a kit from Takara Biotechnology Co. (Dalian, China) for qPCR amplification. SYBR-Green (SYBR-Green I from Invitrogen) was utilized according to the manufacturer's instructions. hsa-miR-195 and U6 snRNA primers were obtained from Ambion; hsa-miR-195 primers, 5'-CCTAGCAGCACAGAAA-3' and 5'-GAGCAGGCTGGA GAA-3'; U6, 5'-CTCGCTTCGGCAGCACATA-3' and 5'-CGC TTCACGAATTTGCGTG-3'. Each sample was analyzed in triplicate and the cycle number (CT) at which the amplicon concentration crossed a defined threshold was determined for each individual miRNA. The relative miR-195 levels were normalized to U6 levels and calculated using the equation $2^{-\Delta \Delta \mathrm{Ct}} \pm$ standard deviation (SD).

Lentivirus carrying Raf-1 siRNA, cell infection and miR-195 mimics and inhibitor. We utilized an online siRNA design software (http://design.RNAi.jp/) to determine Raf-1 target oligonucleotide sequence (5'-GAGACATGAAATCCAA CAA-3'; GenBank \#NM_002880) and synthesized the sense and antisense Raf-1 oligonucleotides according to Shanghai Sangon Biological Corp. (Shanghai, China); siRAF1 sense, 5'-GATCCGAGACATGAAATCCAACAATACTTCCTGTC AGATATTGTTGGATTTCATGTCTCTTTTTG-3' and antisense, 5'-AATTCAAAAAGAGACATGAAATCCAACAAT ATCTGACAGGAAGTATTGTTGGATTTCATGTCTCG-3'. The lentiviral-shRNA vector (pLenOR-GPH Raf-1 vector) was constructed by cloning a PCR-amplified fragment of Raf-1 
Table I. Clinical characteristics of the 30 patients studied.

\begin{tabular}{|c|c|c|}
\hline Characteristics & All patients $(\mathrm{N}=17)$ & $\%$ \\
\hline Age at diagnosis & 49 years $(28-82)$ & \\
\hline Gender & Female & \\
\hline Tumor stage & 6 & \\
\hline T0 & 2 & 35 \\
\hline $\mathrm{T} 1$ & 9 & 12 \\
\hline $\mathrm{T} 2$ & 8 & 53 \\
\hline No & 2 & 47 \\
\hline N1 & 7 & 12 \\
\hline $\mathrm{N} 2$ & 11 & 41 \\
\hline M0 & 6 & 65 \\
\hline M1 & & 35 \\
\hline \multicolumn{3}{|l|}{ ER } \\
\hline Negative & 9 & 53 \\
\hline Positive & 8 & 47 \\
\hline \multicolumn{3}{|l|}{ PR } \\
\hline Negative & 10 & 59 \\
\hline Positive & 7 & 41 \\
\hline \multicolumn{3}{|l|}{ Recurrence } \\
\hline Yes & 10 & 59 \\
\hline No & 7 & 41 \\
\hline
\end{tabular}

siRNA into the BamHI/EcoRI site of pcDNA-GFP and then amplifying the GFP-tagged Raf-1 siRNA with primers flanked by the restriction enzyme sites and cloned into the pLenORGPH. Empty pLenOR-GPH vector, without Raf-1 siRNA, was used as the negative control.

Lentivirus was produced with the Lenti-Pac ${ }^{\mathrm{TM}}$ Lentivirus expression system (Invabio), together with the transfer plasmid pLenOR-GPH-Raf-1, packaging plasmid pRsv-REV, pMDlgpRRE, and pMD2G, all of which are lentivirus shuttle carriers. Recombinant lentiviruses were produced by cotransfection of siRNA-transferring plasmids and plasmids were packaged into 293FT cells with the calcium phosphate method. Subsequently, the cell culture supernatant was harvested after 48-h cultures; debris was dumped by $4,000 \mathrm{x} \mathrm{g}$ centrifugation for $10 \mathrm{~min}$ at $4^{\circ} \mathrm{C}$. The virus was then purified by a Plus-20 kit (Millipore, USA) and stored at $-80^{\circ} \mathrm{C}$. The production of control virus enveloping pLenOR-GPH followed the same protocol.

For titer determination, 293T cells were seeded into 6-well plates at a density of $1 \times 10^{5}$ cells/well. The next day, lentivirus was diluted 10 times in serum-free culture consistently to prepare five concentrations of solution and lentivirus was added in 6-well plates. Cells were harvested after 4 days and the titer of the virus was estimated by the flow cytometric test. Titer [transduction unit $(\mathrm{TU}) / \mathrm{ml}]=$ Cell quantity $\times 10^{5} \mathrm{x}$ GFP cell proportion $\mathrm{x}$ 1,000/M (M, $1 \mu$ l-contained amount of virus).

To infect tumor cells with lentivirus, cells were seeded into 6 -well plates $\left(5 \times 10^{5} /\right.$ well with $2 \mathrm{ml}$ of DMEM containing $10 \%$ FCS) overnight, washed with serum-free DMEM, lenti-Raf-1 storage solution was diluted to appropriate concentrations and then infected with a negative control lentiviral vector or the lentiviral vector carrying Raf-1 siRNA at a multiplicity of infection (MOI) of 20 and added to cells in the presence of $8 \mu \mathrm{g} / \mathrm{ml}$ Polybrene (Sigma, St. Louis, MO, USA). After $12 \mathrm{~h}$ at $37^{\circ} \mathrm{C}$, the cells were washed and $2 \mathrm{ml}$ of fresh growth medium was added. After $72 \mathrm{~h}$, the cells were harvested for analyses.

Plasmids carrying miR-195 mimic or inhibitor were purchased from RiboBio Co., Ltd. (Ghuangzhou, China) and used to transfect breast cancer cells. In brief, cells were plated at a density of $5 \times 10^{5} / \mathrm{ml}$ in 6 -well cell culture plates (BD Biosciences, Mountain View, CA, USA) overnight and then transfected with $50 \mathrm{nM}$ of miR-195 mimic or inhibitor with Lipofectamine ${ }^{\mathrm{TM}} 2000$ and a nonspecific miRNA mimic or inhibitor was used as negative control plasmid. Twenty-four hours later, the cells were collected for further analysis.

MTT cell viability assay. To perform 3-(4,5-dimethylthiazol2-yl)-2,5-diphenyltetrazolium bromide (MTT; Sigma) cell viability assay, MCF-7, MCF-7/ADR and HBL-100 cells infected with lentivirus or transfected with miR-195 plasmid were seeded in 96-well plates $\left(5 \times 10^{3}\right.$ cells/well) and were treated with various concentrations of Adriamycin (10, 50, 100,200 and $500 \mathrm{ng} / \mathrm{ml}$ ) at the indicated time-points. At the end of the experiments, the cell cultures were supplemented with $150 \mu \mathrm{l}$ of $0.5 \mathrm{mg} / \mathrm{ml}$ MTT assay and incubated for an additional $4 \mathrm{~h}$. Then, dimethyl sulfoxide (0.1\% DMSO) was added to the cell culture to dissolve the formazan crystals and incubated for $10 \mathrm{~min}$ at room temperature. The absorbance rate of the cell cultures was read at $570 \mathrm{~nm}$ by using a Vmax Microplate Reader (Bio-Rad, Hercules, CA, USA). Each experiment was performed in triplicate and repeated at least once. Cell viability $(\%)=100 \times(\mathrm{A} 1 / \mathrm{A} 0)$, where $\mathrm{A} 1$ and A0 were the absorbance rate of treated and untreated cells, respectively.

Flow cytometric assay. In vitro cell apoptosis and cell death assays were assessed by flow cytometry with an Annexin V-fluorescein isothiocyanate (FITC)/propidium iodide assay kit (BD Biosciences) according to the manufacturer's protocol. Briefly, cells $\left(5 \times 10^{5}\right.$ cells) were seeded in a 6-well plate and transfected with or without miR-195 mimics or inhibitors, or infected with Raf-1 siRNA lentivirus, or the control lentivirus, and then incubated for $48 \mathrm{~h}$. The medium was then replaced with either fresh medium (control medium) or with medium supplemented with various concentrations of Adriamycin. At the end of experiments, cells were washed twice with phosphate-buffered saline (PBS) and resuspended in Annexin V-binding buffer. Cell suspension was then incubated with $5 \mu \mathrm{l}$ of Annexin V-FITC and incubated for $10 \mathrm{~min}$ at $4^{\circ} \mathrm{C}$ in the dark. After adding $10 \mu \mathrm{l}$ of propidium iodide and incubating for another $10 \mathrm{~min}$ at $4^{\circ} \mathrm{C}$ in the dark, the cells were read by a FACScan flow cytometer (BD Biosciences, San Jose, CA, USA). The fraction of cell population in different quadrants was analyzed using the quadrant statistics, i.e., cells in the lower right quadrant represented early apoptosis and cells in the upper right quadrant represented late apoptotic cells.

Prediction of miRNA targeting genes. The computer-based miRNA target detection programs, i.e., TargetScan (http://www. targetscan.org/), PITA (http://genie.weizmann.ac.il/pubs/mir07/ mir07_data.html), and miRanda (http://www.microrna.org/ 
microrna/home.do), were used to predict miR-195 binding sites of targeting gene mRNA according to the website instructions.

Immunofluorescence staining analysis. MCF-7 and MCF-7/ ADR cells infected with lentivirus or transfected with miR-195 mimic plasmid were seeded in 6 -well plates $\left(5 \times 10^{3}\right.$ cells/well $)$. The cells were fixed in $4 \%$ paraformaldehyde for $10 \mathrm{~min}$ and then incubated in $1 \%$ BSA $/ 10 \%$ normal goat serum $/ 0.3 \mathrm{M}$ glycine in $0.1 \%$ PBS-Tween for $1 \mathrm{~h}$ to permeabilize the cells and block non-specific protein-protein interactions. The cells were incubated with the total Raf-1 (Abcam plc, Cambridge, UK) at a $1 / 200$ dilution for $12 \mathrm{~h}$ at $37^{\circ} \mathrm{C}$ and washed 3 times with $1 \mathrm{X}$ PBS for 5 min each wash. Secondary antibody against total Raf-1 which is conjugated to a green fluorescence probe (Abcam plc) was added and it was incubated for $2 \mathrm{~h}$ at $37^{\circ} \mathrm{C}$.

Protein extraction and western blotting. To extract total cellular protein from breast cancer cell lines, cells were trypsinized, washed with DMEM and centrifuged at $500 \mathrm{x}$ g for $10 \mathrm{~min}$ at $4^{\circ} \mathrm{C}$ and lysed in a lysis buffer containing $20 \mathrm{mmol} / 1$ of Tris- $\mathrm{HCl}$ (pH 7.5), $1 \%$ CHAPS, $150 \mathrm{mmol} / \mathrm{l}$ of NaCl, $10 \%$ glycerol, $1 \mathrm{mmol} / \mathrm{l}$ of $\mathrm{Na}_{3} \mathrm{VO}_{4}$, and the complete protease inhibitor mixture (Roche Diagnostics GmbH, Mannheim, Germany). Samples were placed on ice for $20 \mathrm{~min}$ and then centrifuged at $12,000 \mathrm{x} \mathrm{g}$ for $20 \mathrm{~min}$ at $4^{\circ} \mathrm{C}$. For western blotting, concentration of these protein samples was measured by the BCA (Sigma) method, and equal amounts of samples (30-50 $\mu \mathrm{g} / \mathrm{lane})$ were then loaded onto 8-12\% of SDS-polyacrylamide gel for electrophoresis and subsequently transferred to nitrocellulose membranes (0.45 $\mu \mathrm{m}$; Millipore). Next, the membranes were incubated with $5 \%$ non-fat dry milk for $1 \mathrm{~h}$ at room temperature, followed by incubation with a mouse monoclonal anti-human Raf-1, Bcl-2 or P-glycoprotein antibody at a dilution factor 1:500 (Abcam Inc., Cambridge MA, USA) or mouse antihuman GAPDH monoclonal antibody at a dilution factor 1:500 (Abcam) at $4^{\circ} \mathrm{C}$ overnight. The following day, the membranes were washed with $0.1 \%$ Tween-20 in PBS (PBS-T) and then incubated with a secondary antibody conjugated with goat anti-mouse IgG (1:3,000; Santa Cruz Biotechnology, Inc., Santa Cruz, CA, USA) in blocking buffer for $1 \mathrm{~h}$, followed by exposure to the Enhanced Chemiluminescence Luminal reagent (Santa Cruz Biotechnology, Inc.) briefly and then analyzed with software Image-Pro Plus 5.1 (Media Cybernetics, Inc., Bethesda, MD, USA).

Statistical analysis. The data are expressed as the mean \pm SEM. Statistical comparison of the data was performed using the t-test between two groups or one-way ANOVA or using a post hoc Tukey's test for multiple comparisons between more than two groups. Data were analyzed using an SPSS statistical package for Windows (SPSS Inc., Chicago, IL, USA). A value of $\mathrm{P}<0.05$ was considered to indicate a statistically significant difference.

\section{Results}

Reduced miR-195 expression in breast cancer tissues is associated with chemotherapy response. In this study, we first determined expression levels of miR-195 in HBL-100, MCF-7 and MCF-7/ADR cell lines and our data showed that miR-195
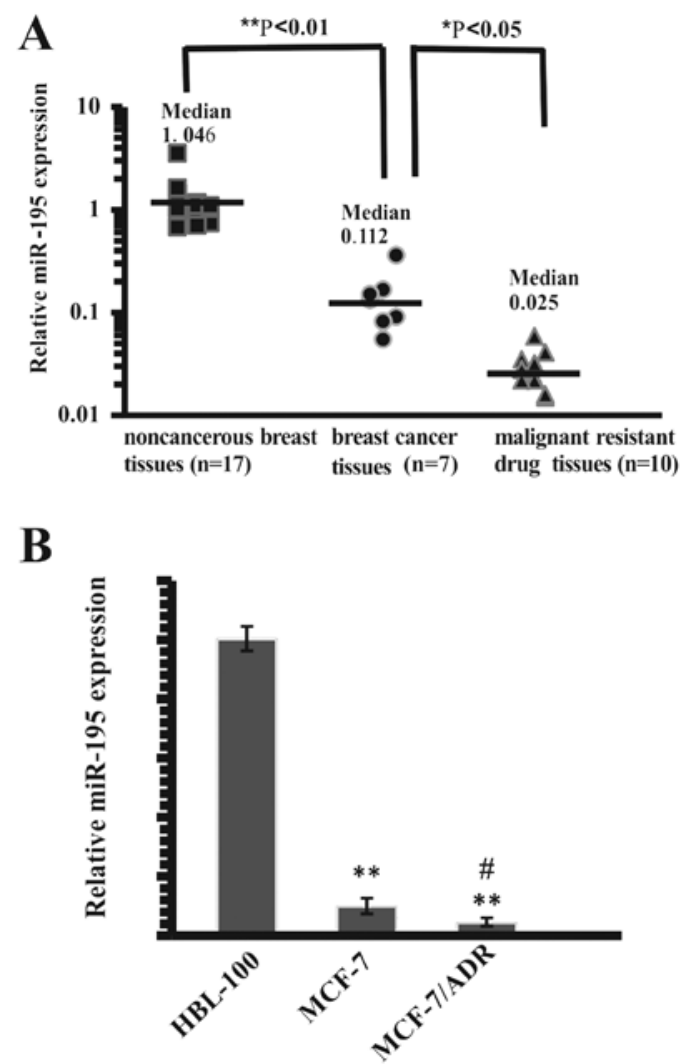

Figure 1. Loss of miR-195 expression in breast cancer tissues and cell lines. (A) qRT-PCR analysis of the mature miR-195 expression in the breast cancer cell line MCF-7 and the multidrug-resistant subline MCF-7/ADR compared with the human mammary gland epithelial cell line HBL-100. Values are shown as means $\pm \mathrm{SD}\left(\mathrm{n}=5,{ }^{*} \mathrm{P}<0.01\right.$, t-test). (B) qRT-PCR analysis of the mature miR-195 expression in breast cancer tissue specimens. Compared to noncancerous breast tissues $(n=17$; median, 1.046), breast cancer tissues $(n=7$; median, 0.112) and drug-resistant breast cancer tissue samples $(n=10$; median, 0.025). The horizontal bars denote the median levels of miR-195 expression. ${ }^{*} \mathrm{P}<0.05$ and ${ }^{* *} \mathrm{P}<0.01$.

expression was significantly lower in MCF-7 and MCF-7/ ADR cells than in HBL-100 (Fig. 1A). Then, we assessed miR-195 expression in clinical breast tissue samples, which were obtained from chemotherapy-sensitive and -resistant breast cancer tissues using qRT-PCR. Our data showed that levels of miR-195 expression were significantly reduced in breast cancer and drug-resistant tissue specimens compared to distant non-cancerous tissues in all 17 cases (Fig. 1B). These data suggest that reduced miR-195 expression may be associated with breast cancer development and drug resistance, particularly Adriamycin resistance.

Association of miR-195 with sensitivity of breast cancer cells to Adriamycin treatment. Fig. 2 shows the sensitivity of breast cancer cells to Adriamycin treatment. Parental breast cancer MCF-7 cells were sensitive to Adriamycin treatment in a dose- and time-dependent manner, whereas the drug-resistant MCF-7 subline MCF-7/ADR cells were resistant to Adriamycin treatment detected by MTT cell viability and flow cytometric apoptosis assays. Moreover, Adriamycin treatment decreased the fraction of MCF-7 cells in G0/G1 and S phases, while they increased the fraction of cells in $\mathrm{G} 2 / \mathrm{M}$ phases, suggesting G2/M arrest of Adriamycin-treated cancer cells (25). 
A

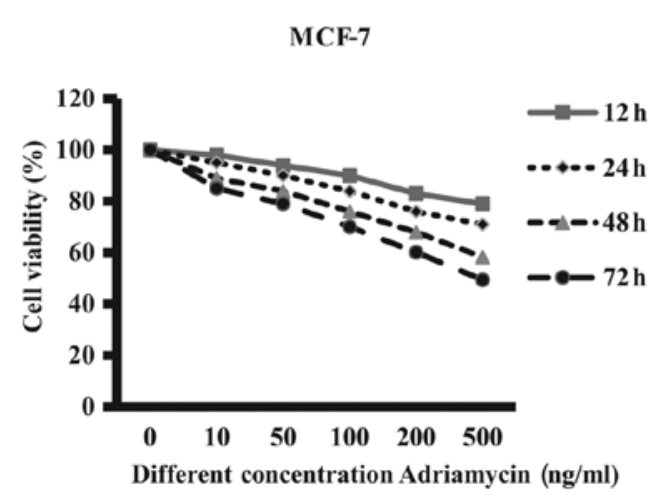

MCF-7/ADR

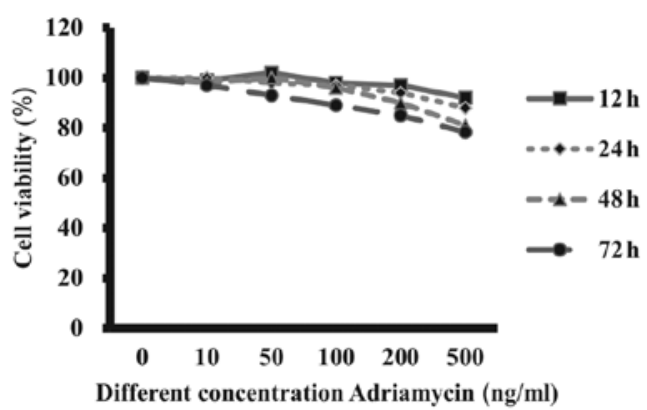

B

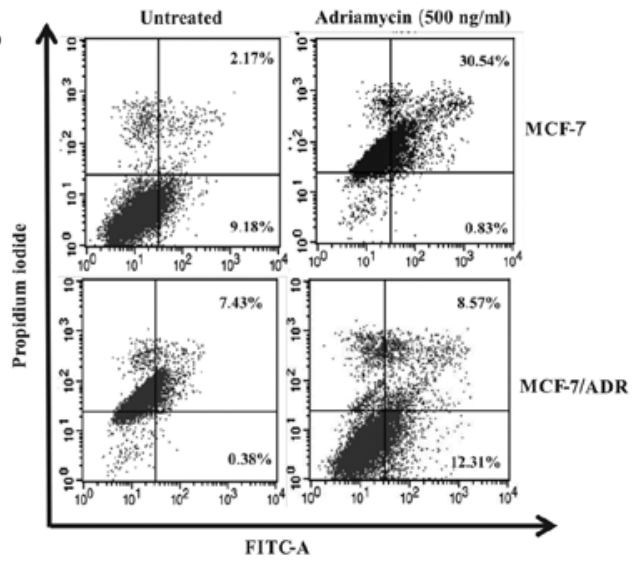

MCF-7

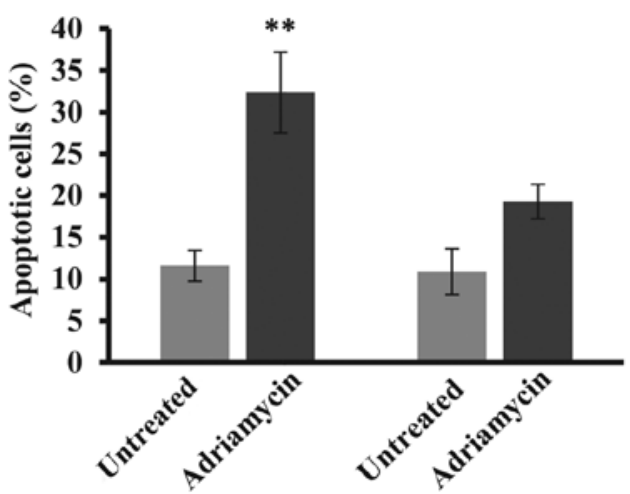

Figure 2. Effect of the chemotherapeutical drug Adriamycin on breast cancer cell lines. (A) MTT assay. Cells were treated with different concentrations of Adriamycin $(\mathrm{ng} / \mathrm{ml})$ for various time-points $(12,24,48$ and $72 \mathrm{~h}$ ). Cell viability was then measured by the MTT assay. (B) Apoptosis flow cytometric assay. Cells treated with $500 \mathrm{ng} / \mathrm{ml}$ Adriamycin for $48 \mathrm{~h}$ were subjected to Annexin V-FITC/PI staining and FACS analysis of apoptosis. Cells in the lower right quadrant represented early apoptosis and cells in the upper right quadrant represented late apoptosis. The data are summarized as the means \pm SD $(n=3$, ${ }^{* *} \mathrm{P}<0.01$, compared to the control cells using t-test).

Association of Raf-1 upregulation with breast cancer cell resistance to Adriamycin. Since miRNA plays a role in the regulation of cell growth, differentiation and apoptosis through inhibition of targeting gene expressions, we performed a GenBank search for miR-195 targeting gene and found that Raf-1 could be a target of miR-195. Thus, we performed western blot analyses to analyze the expression of Raf-1 and Raf-1-related genes in these two breast cancer cell lines and a normal breast cell line. Our data showed that expression of Raf-1 protein levels was significantly higher in breast cancer cells than in normal breast cells (Fig. 3A). However, drug resistant MCF-7/ADR cells expressed higher levels of Raf-1 protein than HBL-100 and MCF-7 cells (Fig. 3A). Similarly, expression of Raf-1-related proteins, such as Bcl-2 and $\mathrm{P}$-glycoprotein, was significantly higher in MCF-7/ADR cells than in HBL-100 and MCF-7 cells (Fig. 3A). Moreover, we assayed Raf-1 expression in breast cancer tissue specimens and found that these 10 chemotherapy-resistant breast cancer tissues expressed high levels of Raf-1 protein compared to the 7 chemotherapy-sensitive breast cancer tissues and the distant normal breast tissues (Fig. 3B). These data suggest that increased expression of Bcl-2 and P-glycoprotein may be due to upregulated and constitutively active Raf-1 protein in breast cancer cells, associated with sensitivity of tumor cells to drug treatment.
Effect of miR-195 on the regulation of breast cancer cell viability and apoptosis. Next, we determined the effects of miR-195 expression on the regulation of breast cancer cell viability and apoptosis by transient transfection of miR-195 mimics and inhibitor into these two breast cancer cell lines. Our data showed that the expression of miR-195 was induced $\sim 3$-fold by the miR-195 mimic compared with the negative control, whereas the miR-195 inhibitor reduced miR-195 expression in these two breast cancer cell lines (Fig. 4A). Cell viability MTT assay showed expression of miR-195 reduced tumor cell viability, whereas the specific miR-195 inhibitor failed to induce tumor cell viability (Fig. 4B). The results show that miR-195 mimics inhibited viability of these cells with an average inhibition rate of $25.6 \%$ for MCF-7 cells and $18.2 \%$ for MCF-7/ADR cells compared to the control cells. Furthermore, transfection of miR-195 mimics clearly induced apoptosis of breast cancer cells in these two breast cancer cell lines compared to the negative control vector-transfected tumor cells (Fig. 4C). These data demonstrated that miR-195 mimics were equally effective in these two breast cancer cell lines, suggesting that miR-195 plays a role in breast cancer resistance to drug treatment.

miR-195 directly targets Raf-1 expression. We have shown the importance of both miR-195 and Raf-1 in breast cancer cell 
Table II. Bioinformatics analysis.

\begin{tabular}{lccccccc}
\hline Organism & RefSeq & Gene name & microRNA & Position & $\mathrm{dG}_{\text {duplex }}$ & $\mathrm{dG}_{\text {open }}(\mathrm{kcal} / \mathrm{mol})$ & $\mathrm{ddG}$ \\
\hline Human & NM_002880 & Raf-1 & hsa-miR-195 & 111 & -12.1 & -12.01 & -0.082 \\
\hline
\end{tabular}

PITA algorithm analysis shows miR-195 targets Raf-1 mRNA site. hsa-miR-195 exhibits a low dG duplex value and low ddG.

A
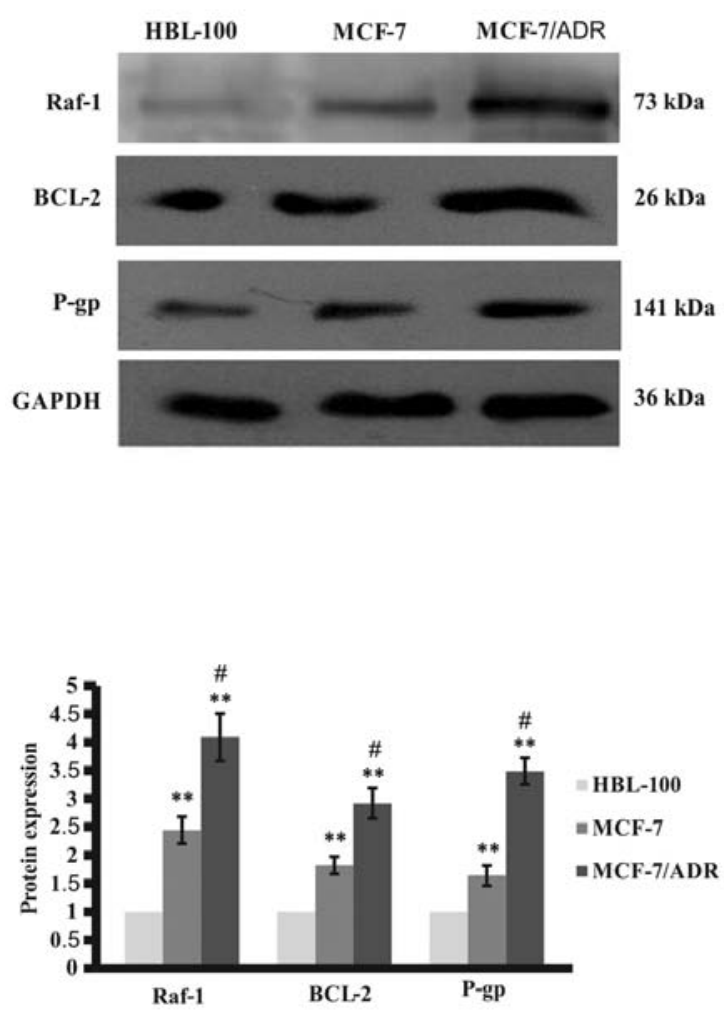

B
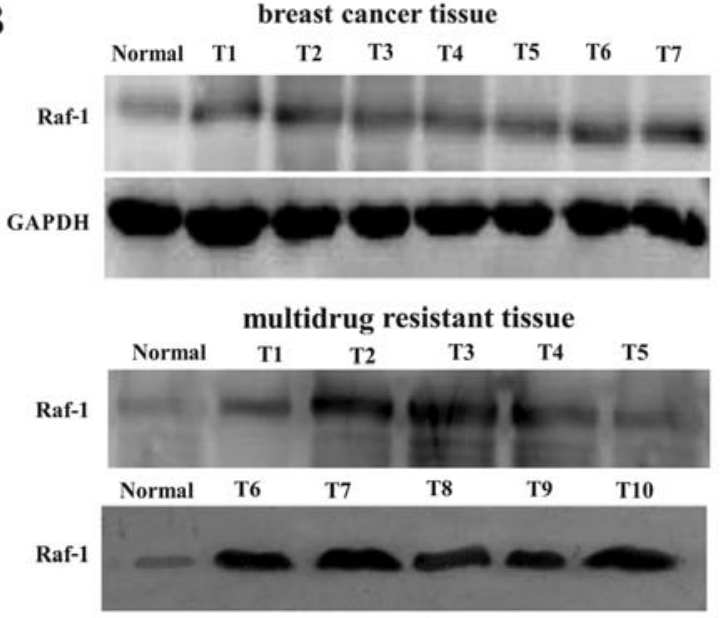

GAPDH
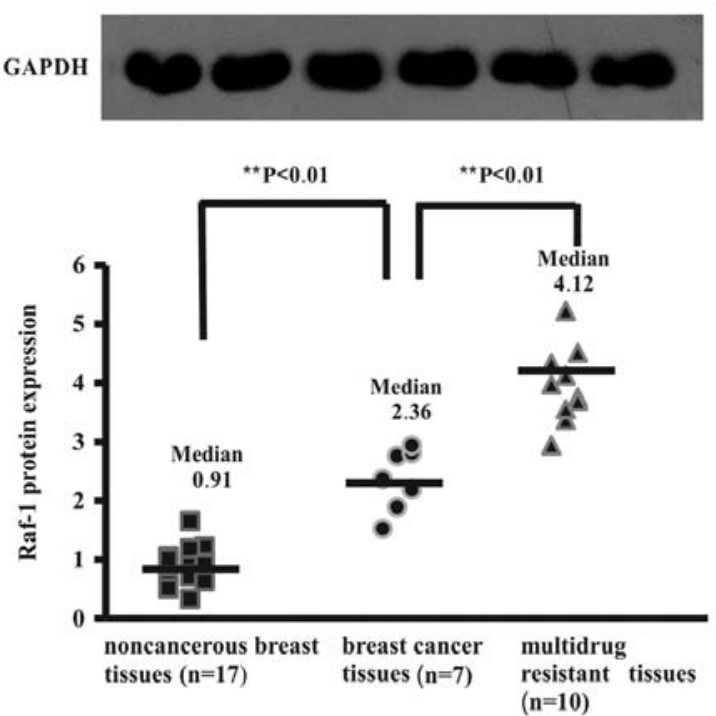

Figure 3. Association of Raf-1, Bcl-2 and P-glycoprotein expression with sensitivity of breast cancer cells to the chemotherapeutical drug Adriamycin (A) Western blot analysis. Breast cancer MCF-7 and MCF-7/ADR cell lines and a normal breast cell line HBL-100 were grown and total cellular protein was extracted and then subjected to western blot analysis. GAPDH was used as a loading control ( ${ }^{* *} \mathrm{P}<0.01$, compared to HBL-100; ${ }^{*} \mathrm{P}<0.01$ compared to MCF-7) (B) Western blot analysis. Breast cancer and normal breast tissue specimens were subjected to western blot analysis of Raf-1 expression. The data showed Raf- 1 expression in noncancerous breast tissues $(n=17$; median, 0.91$)$, breast cancer tissues $(n=7$; median, 1.68) and drug-resistant breast cancer tissue samples $(n=10$; median, 3.64). Horizontal bars denote median $\left({ }^{* *} \mathrm{P}<0.01\right.$, compared to the control cells).

viability and drug resistance. To provide a direct link between these genes, we employed a multiple bioinformatics analysis of miR-195 targeting genes using PITA, TargetScan, and miRanda. PITA analysis showed that miR-195 targeted Raf-1 expression with a lower interaction-free energy $(\mathrm{ddG}, 2.07 \mathrm{kcal} / \mathrm{mol}$; difference between free binding energy of a miRNA to the target, $\mathrm{dG}_{\text {duplex }}$ and free energy lost by opening the target site, $\left.\mathrm{dG}_{\text {open }}\right)$ and the lower free binding energy $\left(\mathrm{dG}_{\text {duplex }},-12.1 \mathrm{kcal} / \mathrm{mol}\right)$ (Table II). The same miR-195 response element (MRE) was identified by TargetScan and the probability of conserved targeting of miRNA (PCT value) was 0.86 , the context score was -0.29 , and the context score percentile was 89 . miRanda data showed that miR-195 has six nucleotides at the 5' 'seed' region complementary to bases 106-112 of the Raf-1 3'-UTR (Fig. 5A). Thus, we detected Raf-1 expression after transfection of miR-195 mimics or inhibitor in these breast cancer cell lines and found that expression of Raf-1 protein level significantly reduced transfection with mim-miR-195 $(68.7 \pm 7.1 \%$ in MCF-7 cells and $61.8 \pm 6.2 \%$ in MCF-7/ADR compared to the negative control cells). By contrast, miR-195 inhibitor transfection also 
A

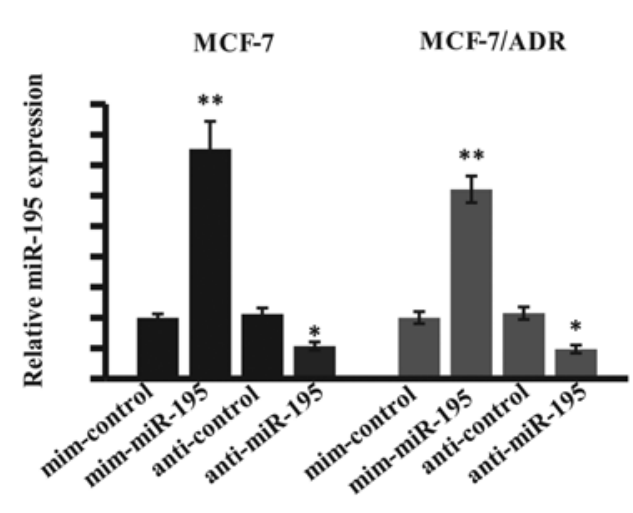

B

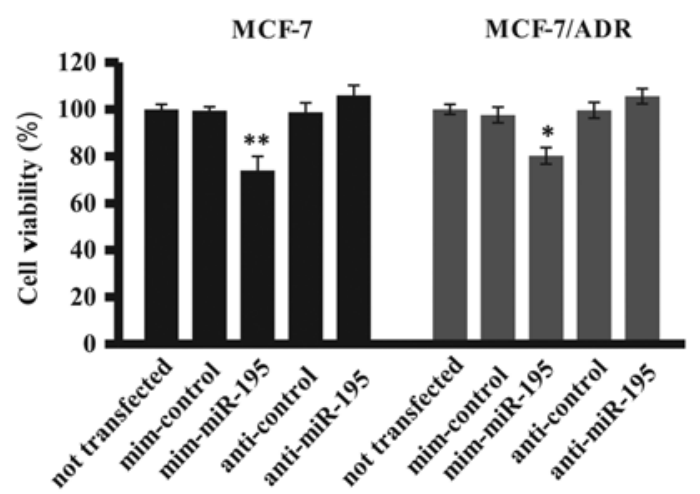

C

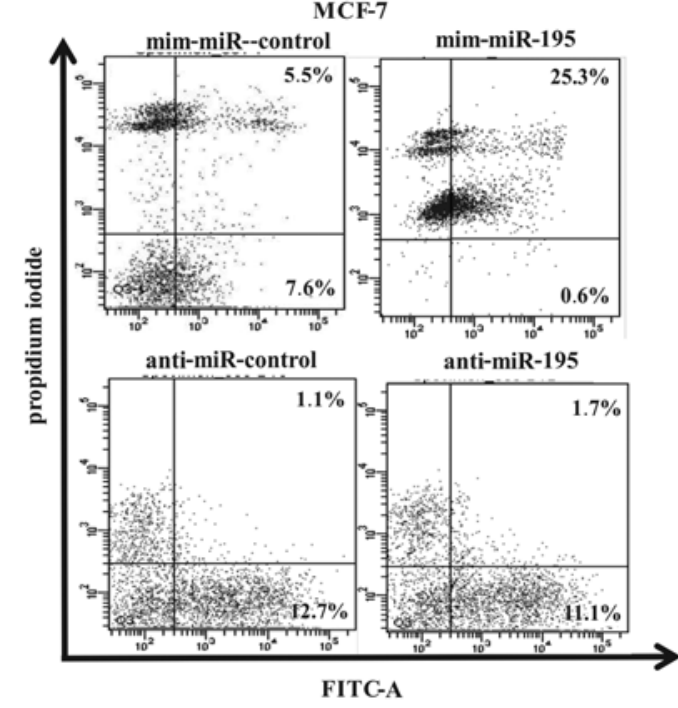

MCF-7/ADR
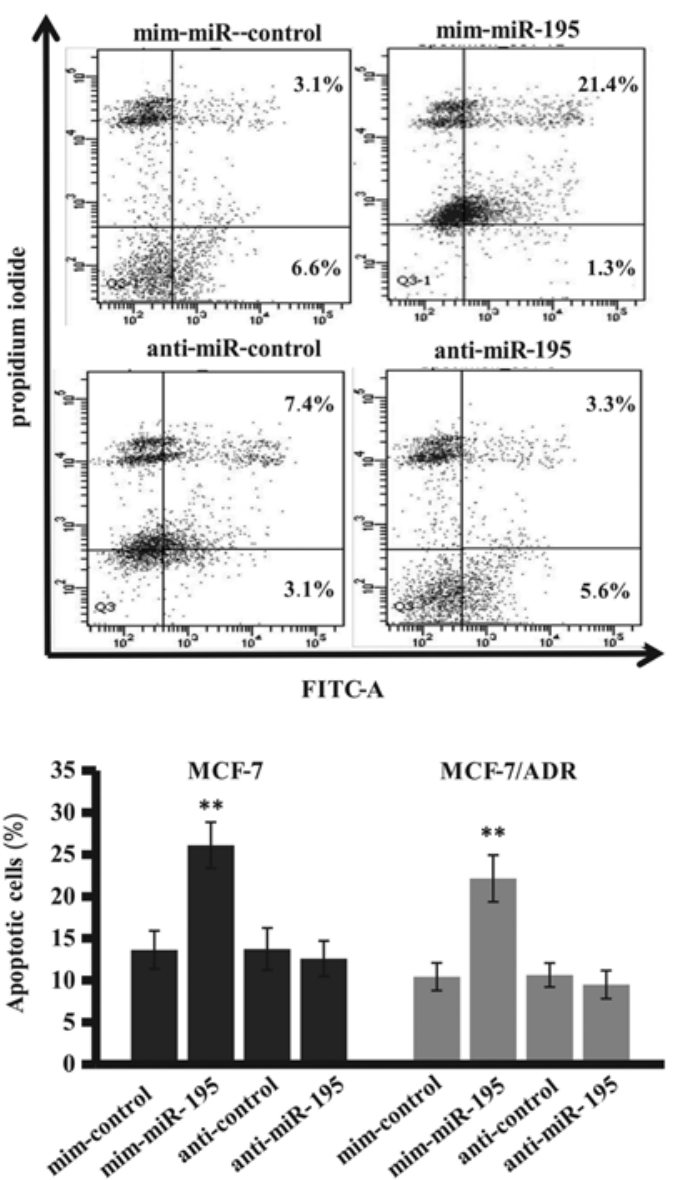

Figure 4. Effect of miR-195 expression on the regulation of breast cancer cell survival and apoptosis. (A) qRT-PCR. Breast cancer cell lines were grown and transiently transfected with miR-195 mimic or inhibitor or negative control. U6 RNA was used for a normalization control. miR-195 mimic increased expression levels of miR-195 relative to the negative control in these two breast cancer cell lines ( $\mathrm{n}=3,{ }^{*} \mathrm{P}<0.05$ and ${ }^{* *} \mathrm{P}<0.01$, compared to the control cells, $\mathrm{t}$-test). (B) MTT assay. The gene-transfected breast cancer cell lines were subjected to cell viability MTT assay. miR-195 mimic transfection significantly inhibited cell viability. ${ }^{*} \mathrm{P}<0.05$ and ${ }^{* *} \mathrm{P}<0.01$, compared to the control cells, t-test. (C) Apoptosis assay. The gene-transfected breast cancer cell lines were subjected to Annexin V-FITC/propidium iodide staining and FACS analysis. The column chart shows the summarized data on effects of miR-195 on apoptosis; miR-195 mimics induced apoptosis of breast cancer cells compared to control cells ( $\mathrm{n}=3,{ }^{* *} \mathrm{P}<0.01$, compared to the control cells).

slightly increased Raf-1 expression (Fig. 5B). In addition, we also analyzed the association of miR-195 with Raf-1 expression in 17 breast cancer tissues and the data showed that miR-195 levels were inversely associated with Raf-1 levels (Fig. 5C).
Knockdown of Raf-1 expression alters ability of breast cancer cell survival. To further investigate the significance of this miR-195-regulated Raf-1 expression in breast cancer cells, we designed and constructed Raf-1 siRNA to knock down 
A

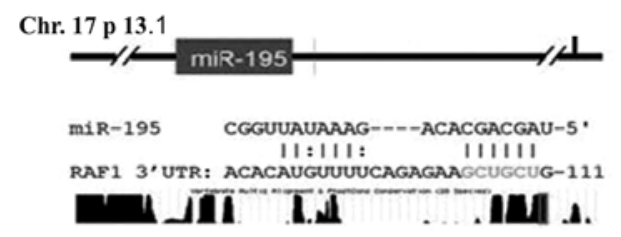

hsa-miR-195 Position 106-112 of Raf -1 3 'UTR Pet 0.86

C

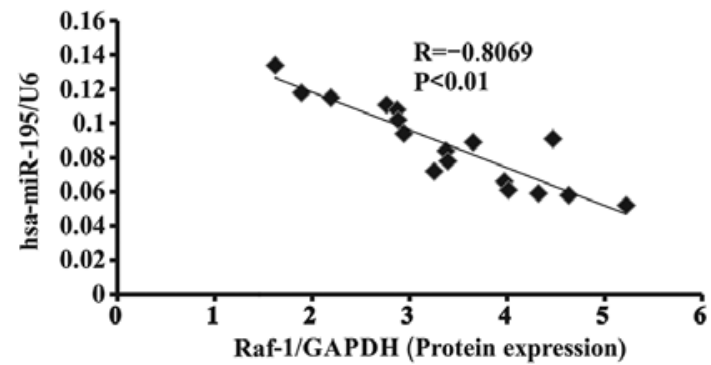

B $\quad$ MCF-7

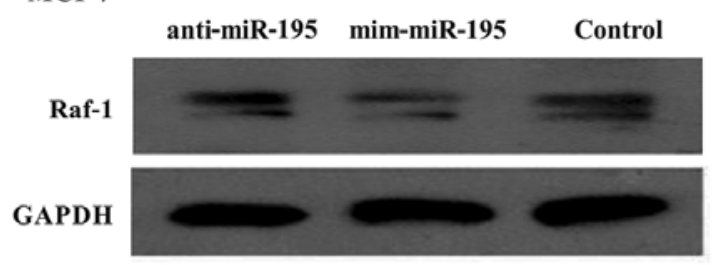

MCF-7/ADR
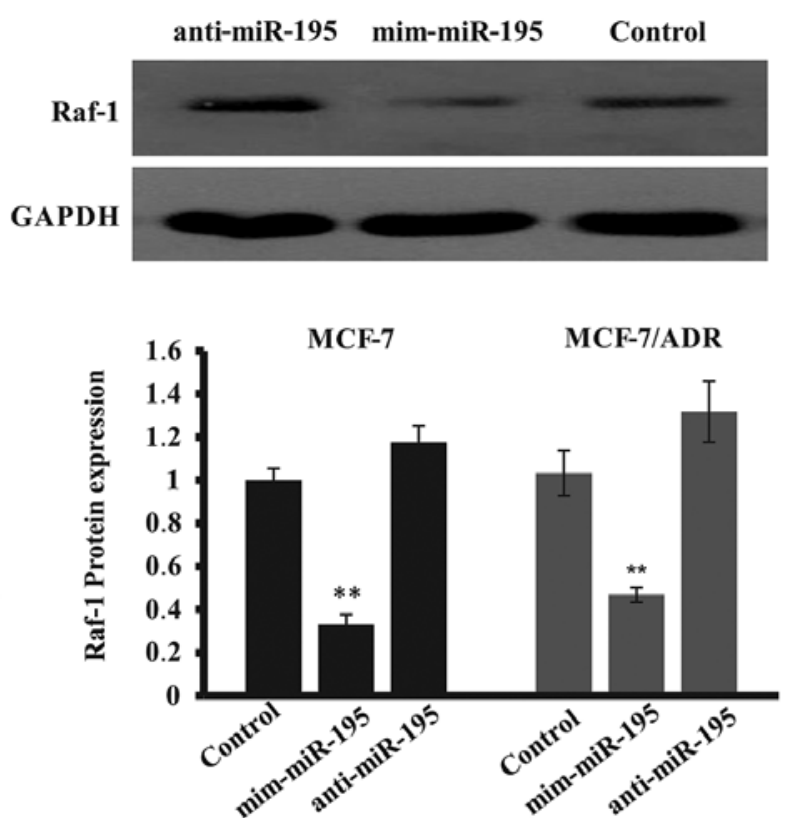

Figure 5. miR-195 targets Raf-1 expression. (A) miRanda analysis. Sites of miR-195 binding to 3'-UTR of Raf-1 are aligned using miRanda v1.0b, i.e., miR-195 has six nucleotides at the 5' 'seed' region that are complementary to 106-112 of Raf-1 3'-UTR. (B) Western blot analysis. Cells transfected with miR-195 mimic or inhibitor or negative control were subjected to western blot analysis. GAPDH was used as a loading control. Expression of Raf-1 protein was reduced in miR-195 mimic-transfected breast cancer cells ( $\left({ }^{* *} \mathrm{P}<0.01\right.$, compared to the control cells). (C) Association of miR-195 expression with Raf-1 expression in 17 breast cancer tissues. The correlation coefficient, $r=-0.8432, \mathrm{P}<0.01$, indicating that there is a strong negative association between miR-195 and Raf- 1 protein expression in breast cancer tissues. Data were analyzed using the Spearman's rank statistical test.

Raf-1 expression. We found that Raf-1 siRNA significantly reduced Raf-1 protein levels $(73.3 \pm 2.8 \%$ in MCF-7 cells and $68.5 \pm 3.4 \%$ in MCF-7/ADR cells) (Fig. 6A), which was similar to transfection with miR-195 mimic (Fig. 5C). We next evaluated the effect of Raf-1 knockdown on the regulation of breast cell viability by transient transfection with miR-195 mimic or siRNA-Raf-1. The data showed that Raf-1 knockdown inhibited breast cancer cell viability (average inhibition rate of $23.4 \%$ for MCF-7 cells and 16.2\% for MCF-7/ADR cells compared to control cells), similar to that of miR-195 mimics transfection (Figs. 6B vs. 4B). We used immunofluorescence staining to examine Raf-1 expression levels in MCF-7 and MCF-7/ADR cells. We also found that the expression of Raf- 1 was markedly reduced with substantially reduced intensity of fluorescence in the cells that transfected with Raf-1 siRNA or miR-195 mimic, whereas non-transfection cells contained more Raf- 1 than the parental cells transfected with Raf-1 siRNA or miR-195 mimic (Fig. 6C).

Expression of miR-195 alters sensitivity of breast cancer cells to anticancer drugs by downregulation of Raf-1 expression. To directly link the effects of miR-195 expression on the regulation of breast cancer cell sensitivity to drug treatment through downregulation of Raf-1 expression, we first determined miR-195 transfection and Adriamycin treatment in these breast cell lines. Our data showed that miR-195 mimic-transfected tumor cells significantly reduced survival rate compared to control cells, whereas anti-miR-195-transfected cell lines slightly increased cell viability compared to control cells (Fig. 7A and B), which showed more additive effects of Adriamycin plus miR-195 mimics on inhibition of tumor cell survival but induction of apoptosis. Moreover, knockdown of Raf-1 expression significantly suppressed the survivability of MCF-7 and MCF-7/ADR cells compared with control vector-transfected cells (Fig. 7A and B). We also found that Raf-1 knockdown enhanced Adriamycin-induced tumor cell apoptosis, i.e., apoptosis rates increased from $30 \pm 3 \%$ in control-siRNA treated to $50 \pm 5 \%$ in MCF-7-Raf-1 siRNA transfected and Adriamycin-treated tumor cells and from $21 \pm 3 \%$ in control-siRNA treated to $40 \pm 4 \%$ in MCF-7/ ADR-Raf-1 siRNA transfected and Adriamycin-treated tumor cells (Fig. 7B). Similar findings were also extended to apoptosis of human MCF-7 and MCF-7/ADR cells after transfection with miR-195 mimic, i.e., the miR-195 mimic 
A $\quad$ MCF-7

siRNA Raf-1 siRNA control not transfected

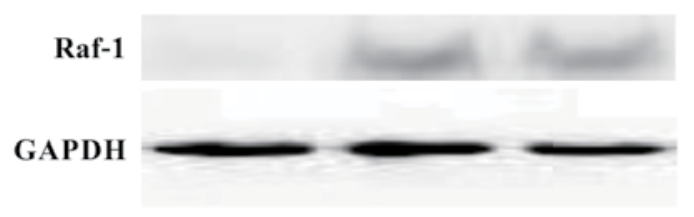

MCF-7/ADR

siRNA Raf-1 siRNA control not transfected
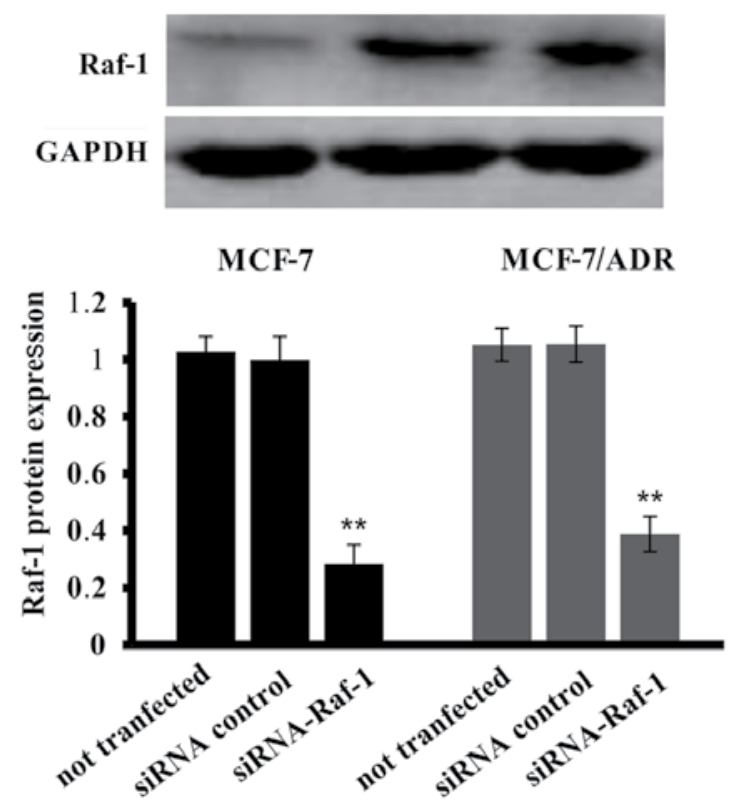

B

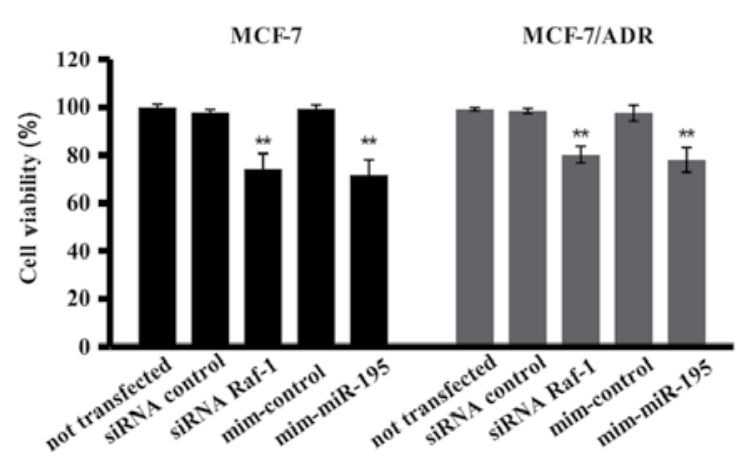

C

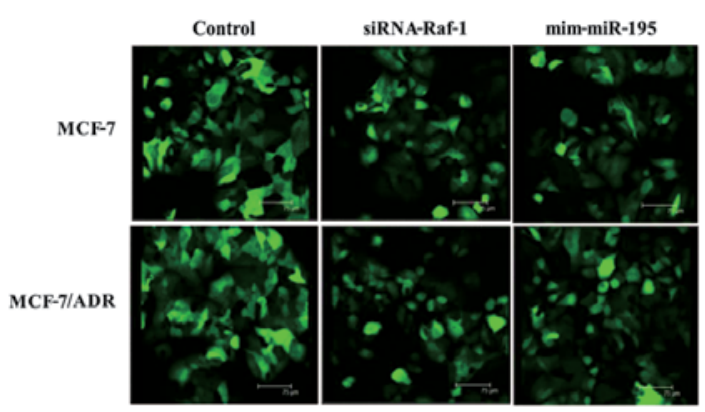

Figure 6. Knockdown of Raf-1 expression alters the survival ability of breast cancer cells. (A) Western blot analysis. Cells were transfected with $50 \mathrm{nM}$ scramble siRNA (siRNA control) or Raf-1 siRNA and non-transfection as a control and then subjected to western blot analysis. GAPDH was used as a loading control. The data are summarized in the graph as a mean of three independent determinations; ${ }^{* *} \mathrm{P}<0.01$, compared to the control cells. (B) MTT assay. Cells were transiently transfected with miR-195 mimic and siRNA-Raf-1 or negative control and then subjected to MTT assay. Data are presented as the percentage of cell viability and summarized as a mean of three independent experiments $\left({ }^{* *} \mathrm{P}<0.01\right.$, compared to the control cells using t-test.). (C) Immunofluorescence staining identified Raf-1 protein expression in MCF-7 and MCF-7/ADR cells. Cells transfected with Raf-1 siRNA or miR-195 mimic, and non-transfection as a control and then subjected to indirect immunofluorescence with anti-Raf-1 antibody (green fluorescence). The expression of Raf-1 was markedly reduced with substantially reduced intensity of fluorescence in the cells that transfected with Raf-1 siRNA or miR-195 mimic, whereas non-transfection cells had significantly higher immunofluorescent expression of Raf-1. Scale bar represents $75 \mu \mathrm{m}$.

significantly enhanced apoptosis of Adriamycin-induced tumor cells compared to the control cells (apoptosis rate from $32 \pm 4$ to $54 \pm 6 \%$ for MCF-7 cells and from $22 \pm 2$ to $42 \pm 4 \%$ for MCF-7/ADR cells) (Fig. 7B). These data suggest that miR-195 expression affected cell sensitivity to Adriamycin and was mediated by suppression of Raf-1 expression.

Furthermore, to understand the miR-195-mediated Raf-1 gene pathway, we found that modulation of miR-195 expression inhibited expression of Raf-1 protein, which in turn affects Bcl-2 and P-glycoprotein expression for changes in cancer cell sensitivity to Adriamycin treatment. Our data showed the changes in expression of Bcl-2 and P-glycoprotein in MCF-7 and MCF-7/ADR cells after transfection with miR-195 mimic and inhibitor or Raf-1-siRNA (Fig. 7C and D). In particular, expression of Bcl-2 and P-glycoprotein was significantly lower in tumor cells transfected with miR-195 mimic than that of the control vector-transfected tumor cells, whereas there was a slight increase in the expression of Bcl-2 and P-glycoprotein in the anti-miR-195-transfected cells. Similarly, Raf-1-siRNA transfection had such effects (Fig. 7C and D). These data demonstrated that expression of miR-195 was inversely associated with Raf-1 expression in these two breast cancer cell lines and miR-195 expression reduced tumor cells survival but increased apoptosis by the downregulation, at least in part, of Raf-1 expression. Meanwhile, expression of Bcl-2 and P-glycoprotein was affected by miR-195 or Raf-1 siRNA, in association with the sensitivity of breast cancer cells to Adriamycin treatment.

\section{Discussion}

Altered expression of miRNAs plays an important role in regulating cell activities, including proliferation, morphogenesis, apoptosis, differentiation as well as cancer development and progression $(14,26)$. Dysregulated expression of miRNA was also reported to play a role in resistance to cancer therapy $(27,28)$. In particular, previous studies have shown aberrant miR-195 expression in various types of human cancer, 
A

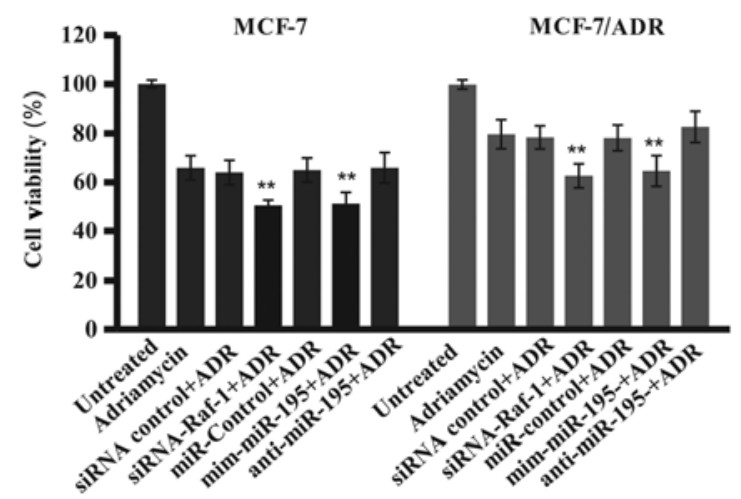

B

MCF-7

mim-control+Adriamycin mim-miR-195+Adriamycin
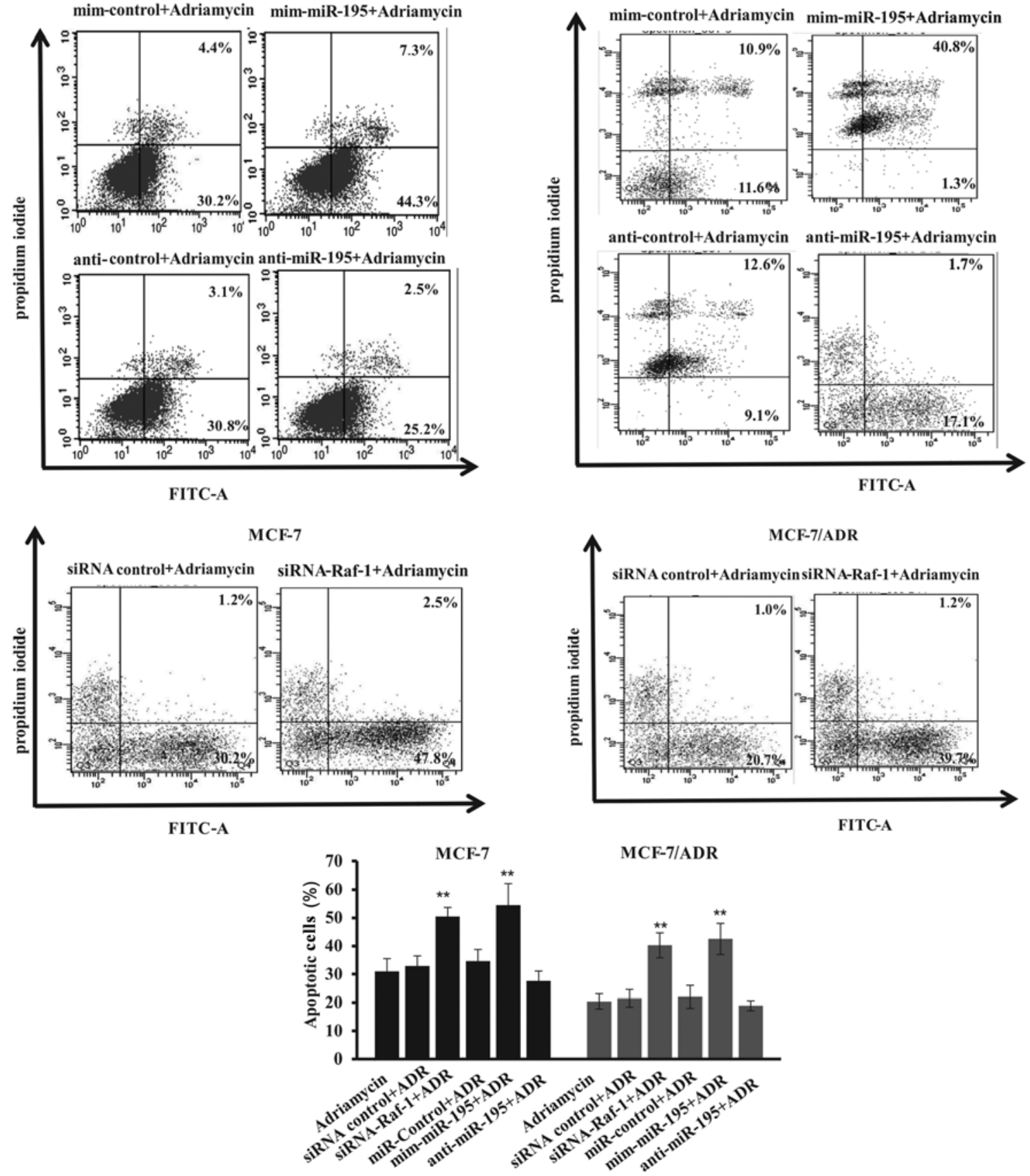

Figure 7. Modulation of miR-195 expression alters sensitivity of breast cancer cells to Adriamycin treatment. (A) MTT assay. MCF-7 and MCF-7/ADR cells were transfected with miR-195 mimic or inhibitor and siRNA-Raf- 1 or control and then treated with Adriamycin ( $500 \mathrm{ng} / \mathrm{ml})$ for $48 \mathrm{~h}$ and subjected to MTT assay. Cells transfected with miR-195 mimics or siRNA-Raf-1 showed a significant reduction in surviving cells compared to control cells, whereas anti-miR-195-transfected cell lines showed a slight increase in cell viability compared to the control cells $\left(n=3,{ }^{* * *} \mathrm{P}<0.01\right.$, compared to the control cells). (B) Apoptosis assay. The duplicated cells from (A) were subjected to Annexin V-FITC/propidium iodide staining and FACS analysis. Column chart summarized the FACS data showing the effect of miR-195 mimic + ADR, inhibitor + ADR or siRNA-Raf-1 + ADR on the percentage of cells apoptosis ( $\mathrm{n}=3$, "** $\mathrm{P}<0.01$, compared to the control cells). 
C

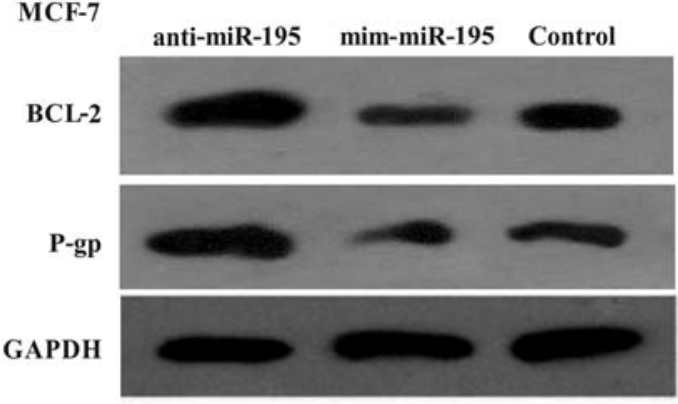

MCF-7

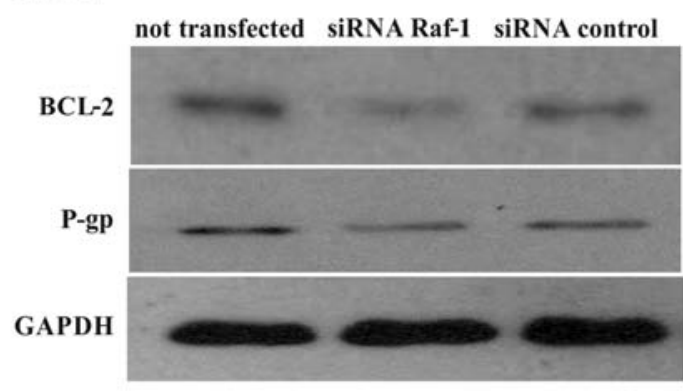

D

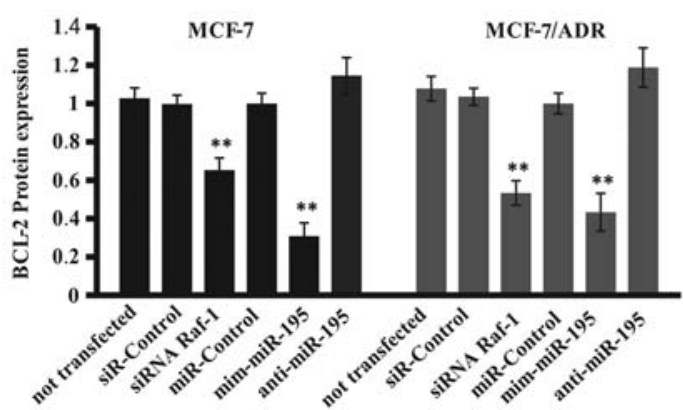

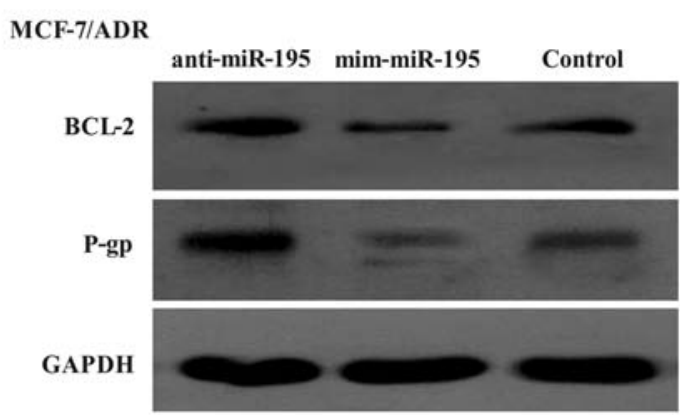

MCF-7/ADR
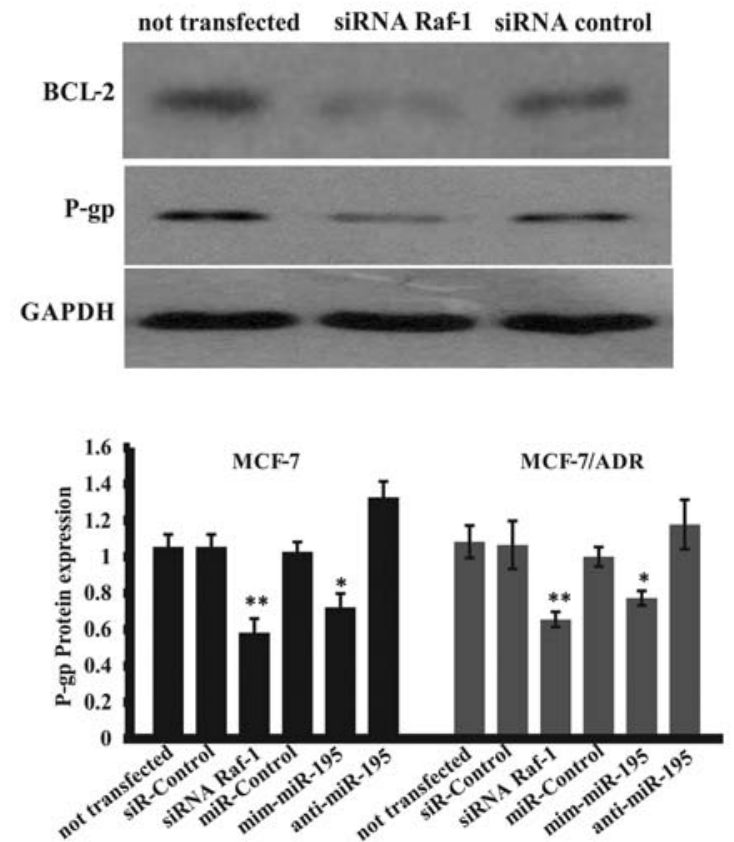

Figure 7. Continued. (C) Western blot analysis. Cells transfected with miR-195 mimic, inhibitor and siRNA-Raf-1 or control were subjected to western blot analysis of Bcl-2 and P-glycoprotein expression. GAPDH was used as a loading control. (D) Summarized data of (C) (n=3, ${ }^{*} \mathrm{P}<0.05$ and ${ }^{* *} \mathrm{P}<0.01$, compared to the control cells).

such as gastric, bladder and breast cancer $(16,17)$, thus, it was reported that miR-195 plays a tumor-suppressor role in human cancer. For example, overexpression of miR-195 in cancer cell lines induced apoptosis and inhibited tumor cell invasiveness in different cancer cell lines (29-31) and modulated cancer cell sensitivity to chemotherapy by targeting the Bcl-w protooncogene in head and neck and liver cancer $(32,33)$. Thus, in the present study, we investigated the effects of miR-195 on the regulation of breast cancer viability, apoptosis and sensitivity to Adriamycin treatment, and then explored the underlying mechanisms by targeting Raf-1 expression and Raf-1-related pathway genes. We found that miR-195 expression was reduced in breast cancer tissue and cells compared to the normal breast tissues and cells and that induction of miR-195 expression promoted apoptosis and inhibited survival of breast cancer cells. Our data also showed that miR-195 is able to bind to 3'-UTR of Raf-1 mRNA to suppress Raf-1 expression, consistent with the finding by Flavin et al (34). Indeed, Subramanian and Yamakawa (35) recently showed that miR-195 is a direct negative regulator of Raf-1 expression and that inhibition of
Raf-1 and MEK kinases simultaneously increased apoptosis of colon cancer cells. Other studies revealed that Raf-1 was overexpressed in breast cancer $(36,37)$. Thus, these findings indicate that suppression of Raf- 1 activities by miR-195 could have profound effects on the suppression of cancer development or progression. In this study, we observed that Raf-1 was highly expressed in drug-resistant breast cancer tissues and cells and that miR-195 levels were inversely associated with Raf-1 expression. Moreover, we found that miR-195 expression or Raf-1 knockdown inhibited breast cancer cell survival and promoted them to apoptosis, and that expression of miR-195 inhibited Raf-1 expression in MCF-7 and MCF-7/ADR cells. In addition, the potential interaction between Raf-1 and miR-195 was confirmed by reversed expression of miR-195 and Raf-1 in MCF-7 and MCF-7/ADR cells. For example, when the miR-195 mimic was transfected into MCF-7 and MCF-7/ADR cells, miR-195 expression was induced and Raf-1 expression was reduced, followed by reduced cell survival and apoptosis induction. These phenomena were consistent with Raf-1 siRNA transfection in MCF-7 and MCF-7/ADR cells. 
However, our data showed that anti-miR-195 was not able to produce the inverse data, which may be because these cell lines used expression of low levels of miR-195. Clinically, miR-195, together with miR-497, was significantly downregulated in cancer tissues and promoters of these two miRNAs were regulated by a common $\mathrm{CpG}$ methylation mechanism or high frequency of loss of heterozygosity on chromosome 17 p13.1 $(38,39)$. This study, therefore, demonstrated that antitumor effects of miR-195 were mediated by targeting of Raf-1 expression in breast cancer cells.

Furthermore, to date, Adriamycin is the major drug used in the clinical treatment of breast cancer. Mechanistically, Adriamycin induces tumor cells to undergo apoptosis and stimulates cytokine production as well (40). However, Adriamycin drug resistance is a significant clinical problem and to make this drug more effective, this drug resistance needs to be overcome. In this study, we showed breast cancer MCF-7 cells were sensitive to Adriamycin, whereas MCF-7/ADR cells were resistant; however, both induction of miR-195 and inhibition of Raf-1 expression sensitized MCF-7/ADR cells to Adriamycin treatment by reduced cell viability and induction of apoptosis. This is consistent with previously reported data that Raf-1 expression was associated with highly aggressive tumors (such as inflammatory breast cancer), protected tumor cells from differentiation and apoptosis, and promoted tumor cell proliferation, invasiveness and chemoresistance $(41,42)$. Furthermore, since Raf-1 has been widely accepted as a drug resistance protein, our data showed that reduced miR-195 expression plays a role in the development of multiple drug resistance by loss of miR-195-suppression of Raf-1. In our previous study, we found that reduced miR-195 expression was significantly associated with advanced clinical stages of breast cancer and was inversely associated with Raf-1 expression in breast cancer (38).

In addition, the present study also showed that expression of Bcl-2 and P-glycoprotein levels was significantly higher in MCF-7/ADR cells than in HBL-100 and MCF-7 cells. Expression of miR-195 or inhibition of Raf-1 expression significantly inhibited expression of Bcl-2 and P-glycoprotein in breast cancer cells, which was associated with sensitivity of tumor cells to Adriamycin treatment. In previous studies, it was observed that an activated Raf-1 was able to upregulate Bcl-2 and P-glycoprotein levels in breast cancer cells $(43,44)$. Anti-apoptosis function of $\mathrm{Bcl}-2$ protein contributed to drug resistance of different types of cancer, while P-glycoprotein protected breast cancer cells from chemotherapy-induced apoptosis $(45,46)$. Thus, the elevated levels of miR-195 in miR-195 mimic-transfected MCF-7 and MCF-7/ADR cells not only downregulated expression of $\mathrm{Bcl}-2$ and P-glycoprotein, but also increased sensitivity of these cells to Adriamycin.

Our present data demonstrated that the induced expression of miR-195 in MCF-7 and MCF-7/ADR cell lines suppressed Raf-1 expression and sensitized tumor cells to Adriamycin treatment, suggesting that targeting of Raf-1 expression using miR-195 may have significant implications for prevention and reversal of breast cancer cell resistance to chemotherapy. However, there may be multiple underlying mechanisms, as previous studies demonstrated crosstalk or interactions between the Ras/Raf/MEK/ERK and Ras/PI3K/PTEN/Akt pathways in the regulation of cell growth, survival and apop- tosis $(47,48)$. Moreover, numerous miRNAs may participate to modulate certain gene expressions as part of a complex network for an anti-apoptotic program in tumor cells resistant to apoptosis-inducing chemotherapeutic agents, and these miRNAs have shown to be dysregulated in breast cancer cells resistant to genotoxic agents (49). Future studies will investigate the effects of miR-195-regulated Raf-1 expression in mediating breast cancer sensitivity to Adriamycin treatment in animal experiments and in clinical trials. Our findings also contribute to the understanding of ADR regulation in cancer cells. Additionally, these findings may be beneficial for further research for predicting ADR in patients and designing personalized therapy for breast carcinoma patients.

\section{Acknowledgements}

This study was supported in part by the National Science Foundation of China (grant no. 31140035), and the Foundation of Chongqing Science and Technology Commission (grant no. CSTC, 2011jjA10060), and was supported by grants from the National Natural Science Foundation of China (NSFC30872770), the Natural Science Foundation Project of CQ CSTC (CSTC, 2011BB5131) and the National Ministry of Education Foundation of China (KJ120327).

\section{References}

1. Jemal A, Bray F, Center MM, et al: Global cancer statistics. CA Cancer J Clin 61: 69-90, 2011.

2. O'Driscoll L and Clynes M: Biomarkers and multiple drug resistance in breast cancer. Curr Cancer Drug Targets 6: 365-384, 2006.

3. Coley HM: Mechanisms and strategies to overcome chemotherapy resistance in metastatic breast cancer. Cancer Treat Rev 34: 378-390, 2008.

4. Gonzalez-Angulo AM, Morales-Vasquez F and Hortobagyi GN: Overview of resistance to systemic therapy in patients with breast cancer. Adv Exp Med Biol 608: 1-22, 2007.

5. Marquette $C$ and Nabell L: Chemotherapy-resistant metastatic breast cancer. Curr Treat Options Oncol 13: 263-275, 2012.

6. Lai EC: MicroRNAs are complementary to 3'UTR sequence motifs that mediate negative post-transcriptional regulation. Nat Genet 30: 363-364, 2002.

7. Guo H, Ingolia NT, Weissman JS and Bartel DP: Mammalian microRNAs predominantly act to decrease target mRNA levels. Nature 466: 835-840, 2010.

8. Sempere LF, Christensen M, Silahtaroglu A, et al: Altered MicroRNA expression confined to specific epithelial cell subpopulations in breast cancer. Cancer Res 67: 11612-11620, 2007.

9. Majumder S and Jacob ST: Emerging role of microRNAs in drug-resistant breast cancer. Gene Expr 15: 141-151, 2011.

10. Kastl L, Brown I and Schofield AC: miRNA-34a is associated with docetaxel resistance in human breast cancer cells. Breast Cancer Res Treat 131: 445-454, 2012.

11. Zhu H, Wu H, Liu X, et al: Role of MicroRNA miR-27a and miR-451 in the regulation of MDR1/P-glycoprotein expression in human cancer cells. Biochem Pharmacol 76: 582-588, 2008.

12. Kovalchuk O, Filkowski J, Meservy J, et al: Involvement of microRNA-451 in resistance of the MCF-7 breast cancer cells to chemotherapeutic drug doxorubicin. Mol Cancer Ther 7: 2152-2159, 2008.

13. Bao L, Hazari S, Mehra S, et al: Increased expression of P-glycoprotein and doxorubicin chemoresistance of metastatic breast cancer is regulated by miR-298. Am J Pathol 180: 2490-2503, 2012.

14. Ng EK, Wong CL, Ma ES and Kwong A: MicroRNAs as new players for diagnosis, prognosis, and therapeutic targets in breast cancer. J Oncol 2009: 305420, 2009.

15. Iorio MV, Casalini P, Tagliabue E, et al: MicroRNA profiling as a tool to understand prognosis, therapy response and resistance in breast cancer. Eur J Cancer 44: 2753-2759, 2008. 
16. Zhang QQ, Xu H, Huang MB, et al: MicroRNA-195 plays a tumor-suppressor role in human glioblastoma cells by targeting signaling pathways involved in cellular proliferation and invasion. Neuro Oncol 14: 278-287, 2012.

17. Fei X, Qi M, Wu B, et al: MicroRNA-195-5p suppresses glucose uptake and proliferation of human bladder cancer T24 cells by regulating GLUT3 expression. FEBS Lett 586: 392-397, 2012.

18. McCubrey JA, Steelman LS, Chappell WH, et al: Roles of the Raf/MEK/ERK pathway in cell growth, malignant transformation and drug resistance. Biochim Biophys Acta 1773: 1263-1284, 2007.

19. Cekanova M, Majidy M, Masi T, et al: Overexpressed Raf-1 and phosphorylated cyclic adenosine 3'-5'-monophosphatate response element-binding protein are early markers for lung adenocarcinoma. Cancer 109: 1164-1173, 2007

20. Hoyle PE, Moye PW, Steelman LS, et al: Differential abilities of the Raf family of protein kinases to abrogate cytokine dependency and prevent apoptosis in murine hematopoietic cells by a MEK1-dependent mechanism. Leukemia 14: 642-656, 2000.

21. Chang F, Steelman LS and McCubrey JA: Raf-induced cell cycle progression in Human TF-1hematopoietic cells. Cell Cycle 1: 220-226, 2002

22. Hwang YH, Choi JY, Kim S, et al: Overexpression of c-raf-1 proto-oncogene in liver cirrhosis and hepatocellular carcinoma. Hepatol Res 29: 113-121, 2004.

23. Steelman LS, Chappell WH, Abrams SL, et al: Roles of the Raf/ MEK/ERK and PI3K/PTEN/Akt/mTOR pathways in controlling growth and sensitivity to therapy-implications for cancer and aging. Aging 3: 192-222, 2011.

24. Meslin F, Hamaï A, Gao P, et al: Silencing of prion protein sensitizes breast adriamycin-resistant carcinoma cells to TRAILmediated cell death. Cancer Res 67: 10910-10919, 2007.

25. Lu C, Shao C, Cobos E, et al: Chemotherapeutic sensitization of leptomycin B resistant lung cancer cells by pretreatment with doxorubicin. PLoS One 7: e32895, 2012.

26. Calin GA and Croce CM: MicroRNA signatures in human cancers. Nat Rev Cancer 6: 857-866, 2006.

27. Blenkiron C, Goldstein LD, Thorne NP, Spiteri I, et al: MicroRNA expression profiling of human breast cancer identifies new markers of tumor subtype. Genome Biol 8: R214, 2007.

28. Hannafon BN, Sebastiani P, de las Morenas A, et al: Expression of microRNA and their gene targets are dysregulated in preinvasive breast cancer. Breast Cancer Res 13: R24, 2011.

29. Waters PS, McDermott AM, Wall D, et al: Relationship between circulating and tissue microRNAs in a murine model of breast cancer. PLoS One 7: e50459, 2012.

30. Liu L, Chen L, Xu Y, et al: microRNA-195 promotes apoptosis and suppresses tumorigenicity of human colorectal cancer cells. Biochem Biophys Res Commun 400: 236-240, 2010.

31. Xu T, Zhu Y, Xiong Y, et al: MicroRNA-195 suppresses tumorigenicity and regulates G1/S transition of human hepatocellular carcinoma cells. Hepatology 50: 113-121, 2009.

32. Dai Y, Xie CH, Neis JP, et al: MicroRNA expression profiles of head and neck squamous cell carcinoma with docetaxel-induced multidrug resistance. Head Neck 33: 786-791, 2011.

33. Yang X, Yin J, Yu J, et al: miRNA-195 sensitizes human hepatocellular carcinoma cells to 5-FU by targeting BCL-w. Oncol Rep 27: $250-257,2012$
34. Flavin RJ, Smyth PC, Laios A, et al: Potentially important microRNA cluster on chromosome $17 \mathrm{p} 13.1$ in primary peritoneal carcinoma. Mod Pathol 22: 197-205, 2009.

35. Subramanian RR and Yamakawa A: Combination therapy targeting Raf-1 and MEK causes apoptosis of HCT116 colon cancer cells. Int J Oncol 41: 1855-1862, 2012.

36. Monazzam A, Razifar P, Ide S, et al: Evaluation of the Hsp90 inhibitor NVP-AUY922 in multicellular tumour spheroids with respect to effects on growth and PET tracer uptake. Nucl Med Biol 36: 335-342, 2009.

37. Leicht DT, Balan V, Kaplun A, et al: Raf kinases: function, regulation and role in human cancer. Biochim Biophys Acta 1773: 1196-1212, 2007.

38. Li D, Zhao Y, Liu C, et al: Analysis of MiR-195 and MiR-497 expression, regulation and role in breast cancer. Clin Cancer Res 17: 1722-1730, 2011

39. Bandera CA, Muto MG, Welch WR, et al: Genetic imbalance on chromosome 17 in papillary serous carcinoma of the peritoneum. Oncogene 16: 3455-3459, 1998.

40. Ghebeh H,Lehe C, Barhoush E, et al: Doxorubicin downregulates cell surface B7-H1 expression and upregulates its nuclear expression in breast cancer cells: role of B7-H1 as an anti-apoptotic molecule. Breast Cancer Res 12: R48, 2010.

41. Wang X, Thomson SR, Starkey JD, et al: Transforming growth factor beta1 is upregulated by activated Raf in skeletal myoblasts but does not contribute to the differentiation-defective phenotype. J Biol Chem 279: 2528-2534, 2004.

42. Leontovich AA, Zhang S, Quatraro C, et al: Raf-1 oncogenic signaling is linked to activation of mesenchymal to epithelial transition pathway in metastatic breast cancer cells. Int J Oncol 40: 1858-1864, 2012.

43. Weinstein-Oppenheimer CR, Henriquez-Roldan CF, Davis JM, et al: Role of the Raf signal transduction cascade in the in vitro resistance to the anticancer drug doxorubicin. Clin Cancer Res 7: 2898-2907, 2001

44. Anderson LR, Sutherland RL and Butt AJ: BAG-1 overexpression attenuates luminal apoptosis in MCF-10A mammary epithelial cells through enhanced RAF-1 activation. Oncogene 29: 527-538, 2010.

45. Bodur $\mathrm{C}$ and Basaga $\mathrm{H}$ : Bcl-2 inhibitors: emerging drugs in cancer therapy. Curr Med Chem 19: 1804-1820, 2012.

46. Shen Y, Chu Y, Yang Y and Wang Z: Mitochondrial localization of P-glycoprotein in human breast cancer cell line MCF-7/ADM and its functional characterization. Oncol Rep 27: 1535-1540, 2012.

47. Gollob JA, Wilhelm S, Carter C and Kelley SL: Role of Raf kinase in cancer: therapeutic potential of targeting the Raf/MEK/ERK signal transduction pathway. Semin Oncol 33: 392-406, 2006.

48. Singh R and Saini N: Downregulation of BCL2 by miRNAs augments drug-induced apoptosis - a combined computational and experimental approach. J Cell Sci 125: 1568-1578, 2011.

49. Neelakandan K, Babu P and Nair S: Emerging roles for modulation of microRNA signatures in cancer chemoprevention. Curr Cancer Drug Targets 12: 716-740, 2012. 